\title{
SOME NOTES ON NESTING GREAT HORNED OWLS
}

\author{
by Chris Rees, No. 2 - $13027-83$ St., Edmonton \\ Photographs by the Author
}

Over the past eight years I have been studying and photographing Great Horned Owls. The following notes on a 1969 nest include some observations made over this period.

On March 16, 1969 near Edmonton I found a nest about 25 feet above the ground in a tree without any branches obscuring the view from the front. With several friends I returned to the site early in April to erect a photographic tower. The first night spent in the blind was April 7. The nest at this time contained three eggs. (Although it is always difficult to work with birds still on eggs, Horned Owls seem to be most aggressive for a period of about a week before and a week after the eggs hatch. This period of aggressiveness evidently corresponds to a maximum degree of possessiveness on the part of the adults toward their offspring.) Once I was in the blind the female owl quickly returned to the nest.

From about $7: 30$ p.m. until 8:00 p.m. the male hooted almost continuously. Around 8:00 p.m. he must have gone hunting, for I could not hear him calling or moving. He returned about 8:45 and came in close to the nest. The male hooted several times and the female on the nest answered with a low, chickenlike clucking. The two birds kept up this hooting and clucking for the next half hour. During this time the female also hooted several times. After $9: 15$ the birds fell silent until about $10: 30$ when the male hooted about 10

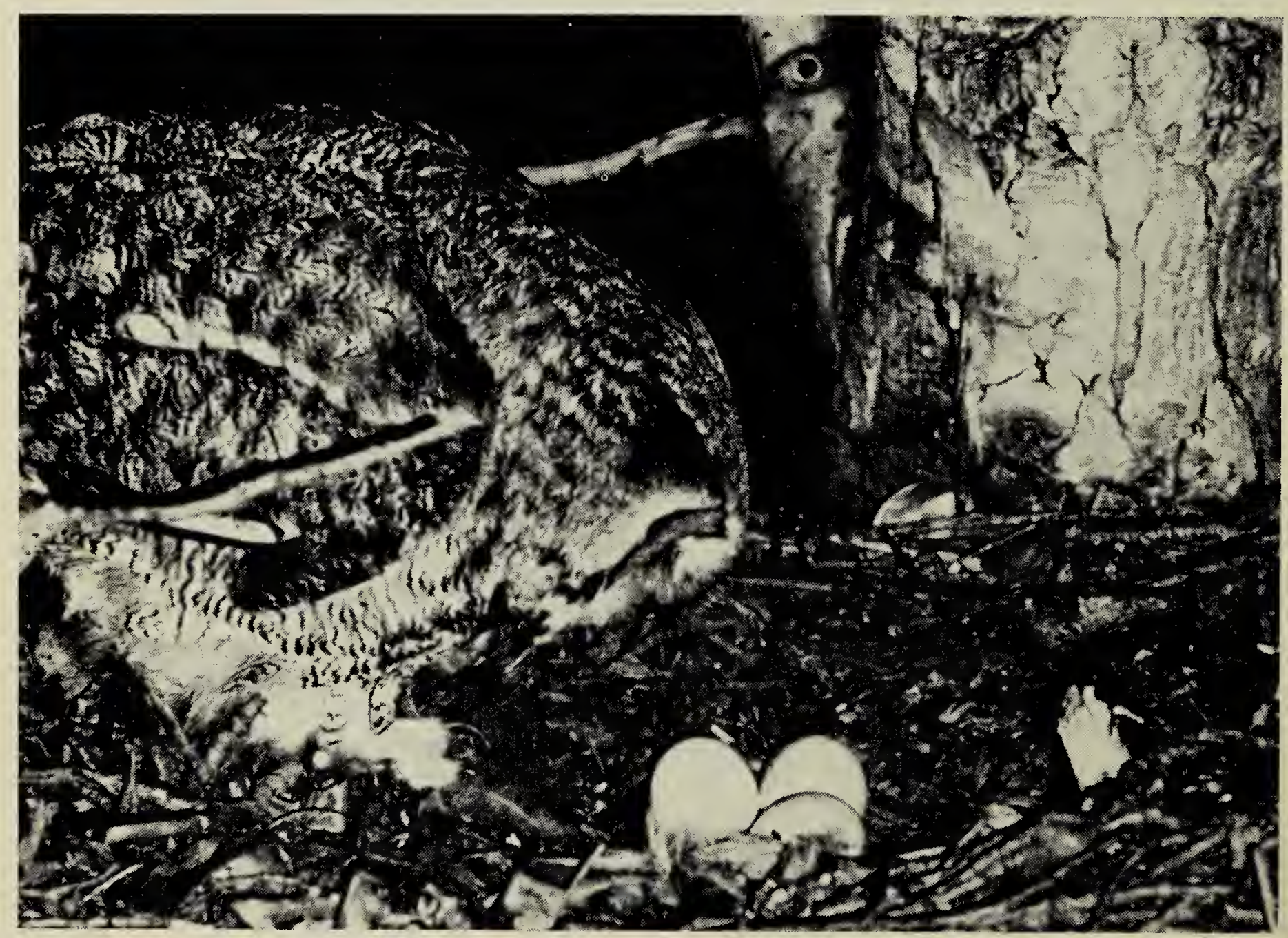

Female Great Horned Owl inspects eggs upon returning to nest. 


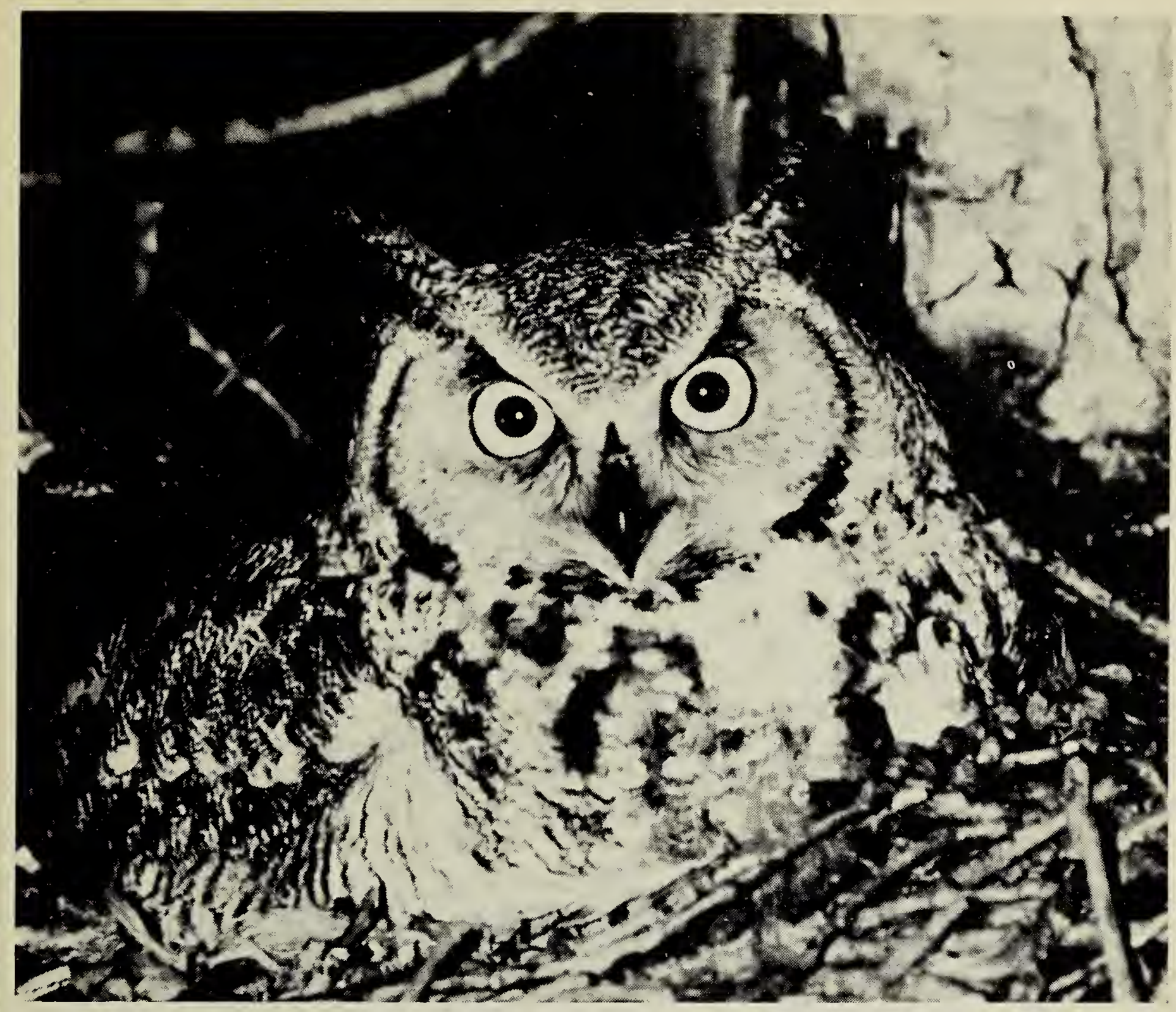

Incubating Great Horned Owl female.

times then once again was quiet.

On the nights of April 9 and 16 the birds were quiet and completely inactive. On the latter night one egg was pipped and the chick peeped softly.

All three eggs had hatched by April 20 and that night proved to be one of the most eventful I had ever spent with Horned Owls. As soon as I was settled in the blind, the female returned to the nest. She was an affectionate mother. Carefully she covered the young and while brooding would occasionally raise herself up and rub the young with her face disk. About 8:00 p.m. the male hooted and the female instantly answered with the food call, a long, drawn-out hiss. The chicks also started to peep. The male did not return with food until almost 9:00 p.m. At that time he brought a mouse to the female, hooted while on the nest, and was gone again. The young became extremely excited, peeping and squirming under the brooding parent. Now and again a little face would peek out from between her breast feathers but each time this occurred she would shuffle and cover the young up again. The female tore the mouse into small pieces and fed the young, eating little herself. Once the mouse was eaten, the young settled down and went to sleep. The male, meanwhile, was off hunting and could be heard hooting from various locations.

After the young are about three weeks of age the adults do not brood anymore for the young are by this time well covered with insulating and protective down and feathers. The description of a typical night for this period follows. Between 9:00 and 
11:00 p.m. the adults would make six visits to the nest, each time bringing a meadow vole. One of the young would grab the vole from the adult and swallow it whole. The young would be active all the while, walking around, picking up sticks and bones and peering over the edge of the nest. With the arrival of the old birds the young would become even more active, bobbing their heads and calling. After 11:00 p.m. and for the rest of the night, until the first greying shadows appeared in the woods, the birds would be quiet. The young would snuggle down in the nest, while the adults would sit close by, calling softly from time to time. Feeding would begin again at the break of dawn. On the morning of May 14 the adults made only three visits to the nest. Each time a vole was brought in.

The wings gradually develop until at about five or six weeks of age the young venture out onto branches around the nest. Sometimes they return to the nest for feeding but after a few more days the adults go directly to the hunger calls of the young and the young no longer return to the nest. I found one young that had left the nest at the end of May. An adult was close at hand and was fierce in its defense. It approached menacingly close, clicking its bill and screaming. When I did not back down, it carried the act further by feigning injury and flopping around on the ground. The young bird put up a valiant defense, fluffing himself up and turning his wings to look large and vicious. He clicked his bill and hissed, an act that was no bluff, for, when I got too close, he quickly and painfully grabbed my hand with both feet. At this point the adult approached to within five feet of my head and sat clicking and screaming. I beat a hasty retreat.

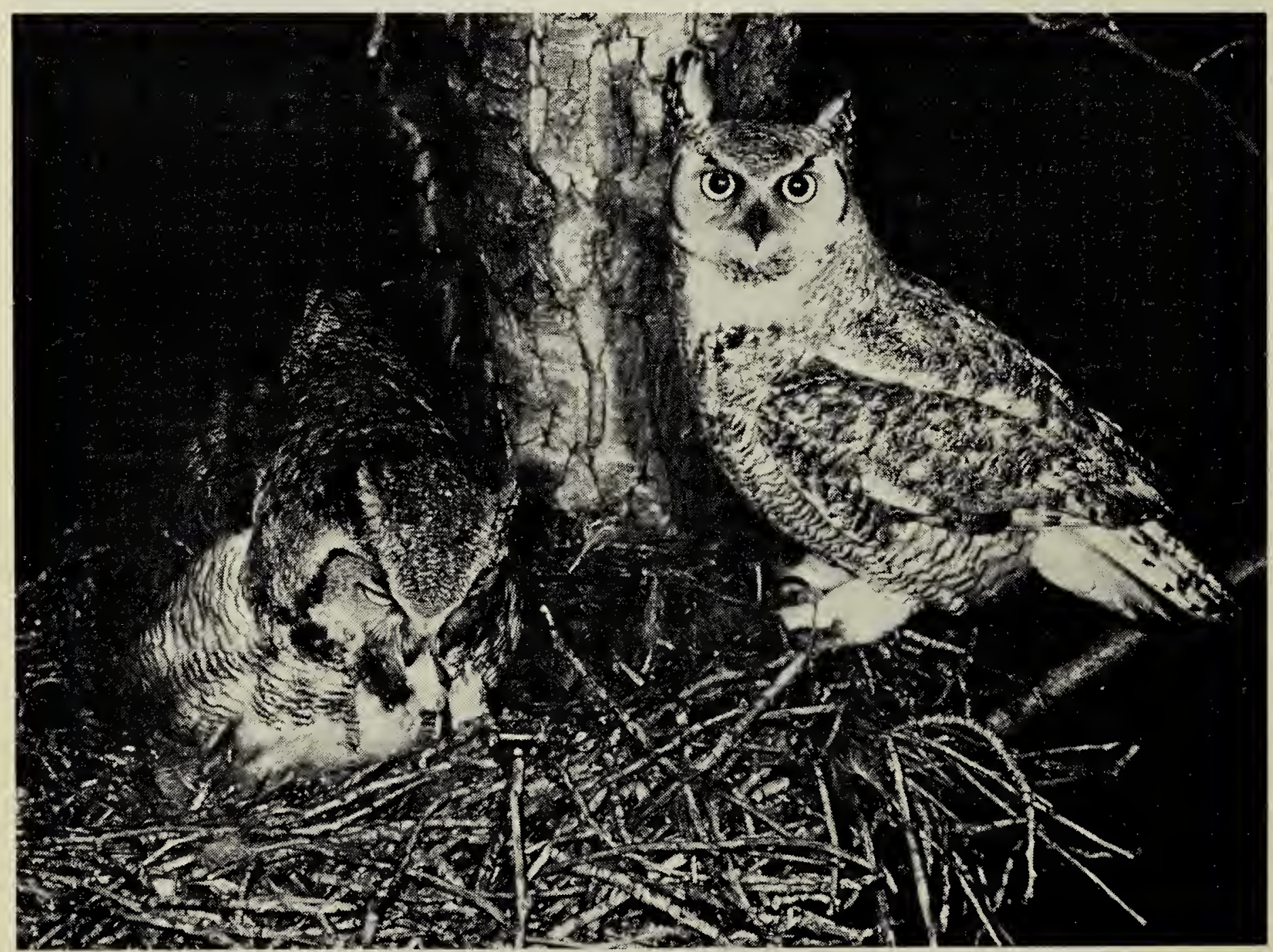

Male Great Horned Owl pauses on edge of nest after delivering a deer mouse to the female. 